\title{
Schizophrenia, an IIIness and a metaphor: analysis of the use of the term 'schizophrenia' in the UK national newspapers
}

\author{
Arun K Chopra ${ }^{1} \quad$ Gillian A Doody²
}

J R Soc Med 2007;100:423-426

\section{SUMMARY}

Objective To determine whether schizophrenia is a commonly used 'illness as metaphor', to compare the use of schizophrenia and cancer as illnesses as metaphor, and to determine if there is a difference in such usage between the UK and USA.

Design An examination of articles published in the British press.

Setting 600 articles from six British newspapers: the Times, the Daily Telegraph, the Guardian, the Mirror, the Sun and the Daily Mail.

Main outcome measures Use of schizophrenia and cancer as metaphors.

Results Schizophrenia was more likely to be metaphorized than cancer $(P<0.001)$ in the UK press, but was less likely to be used as metaphor in the UK press than in the US press $(P<0.001) .11 \%$ of articles containing the term schizophrenia used the word as a metaphor.

Conclusions Clinicians need to be aware that patients, carers and the public might have a different understanding of the word we use as a diagnosis.

\section{INTRODUCTION}

In 1977 the American writer Susan Sontag described how illnesses whose aetiologies are considered mysterious are prone to be used as metaphors. ${ }^{1}$ Using examples from literature she illustrated how in the nineteenth century consumption (tuberculosis) was the illness most associated with metaphorical use, whereas in the mid to late twentieth century cancer was the chosen 'illness as metaphor'. Her view that the metaphorical use of illness makes the illness shameful, with the implication that this could lead to stigmatization, has been influential. Although she admitted that she had done no systematic research for her bookinstead relying on her extensive knowledge of literatureSontag's intellectual reputation and persuasive prose led to

${ }^{1}$ Specialist Registrar, Mental Health Unit, Derby City General Hospital, Uttoxeter Road, Derby DE22 3NE

${ }^{2}$ Clinical Associate Professor in Psychiatry, Nottingham University

Correspondence to: Arun Chopra

Email: arun2111@hotmail.com an uncritical acceptance of her view. Although subsequent empirical research has challenged her view, the negative perceptions of illness may also have improved with the medical advances that have occurred since Sontag first described the metaphors which surround illness. ${ }^{2}$ Sontag's work suggests that misuse of metaphors is a reflection of ongoing stigmatizing beliefs; therefore metaphors which involve mental disorders are more likely to appear than those involving less stigmatized conditions.

Research from the United States, ${ }^{3}$ Germany ${ }^{4}$ and Switzerland $^{5}$ reported that $28 \%, 58 \%$ and $31 \%$, respectively, of the use of the word schizophrenia in newspapers was metaphorical. The US researchers also reported that cancer was used as a metaphor in only $1.3 \%$ of articles. This led them to suggest that schizophrenia is the new illness as metaphor.

This study first examines whether schizophrenia is the new illness as metaphor in the UK by comparing the metaphorical use of schizophrenia to cancer in UK newspapers; second examines any differences between broadsheets and tabloids in this use; and finally compares the use of schizophrenia as a metaphor in the UK and US newspapers.

\section{METHOD}

Using the Lexis-Nexis Professional database, six British newspapers from across the political spectrum were searched for the terms 'schizophrenia' or 'schizophrenic'. The newspapers consisted of three broadsheets (The Times, The Daily Telegraph and The Guardian) and three tabloids (The Mirror, Sun and Daily Mail. The 600 most recent articles containing the search terms were obtained. The use of the word in the first sentence in each article in which it appeared was then examined, and each article was categorized according to contextual use. The contextual categories included:

- Educational/prevention or management related articles, focusing on causes, symptoms, treatments or medication;

- Incidental reference, where the disease or patient is not the main focus of the article but is mentioned (e.g. 'Peter's friend also suffers from schizophrenia', or 'the film touches on topics such as schizophrenia'); 
- Human interest, where the illness or a person with schizophrenia is the main focus of the article;

- Medical news, where pharmaceutical company-related news is reported;

- Metaphorical, where the term is used as a metaphor (e.g. the weather will be schizophrenic);

- Charity related;

- Obituary;

- Medically inappropriate (e.g. schizophrenia is a form of depression).

The categories used and the method followed were similar to those described by American researchers ${ }^{3}$ in their study of the use of schizophrenia in US newspapers. In a separate search, the 600 most recent articles containing the words 'cancer' or 'cancerous' were similarly obtained and categorized.

Statistical Package for the Social Sciences for Windows, Version 14 (SPSS Inc., Chicago, USA) was used to perform chi-square tests to identify differences between the use of schizophrenia and cancer as metaphors in the UK newspapers; tabloid and broadsheet metaphorical use, and UK and US metaphorical use.

\section{RESULTS}

The 600 articles containing the words schizophrenia or schizophrenic were obtained between 01 August 2004 and 05 November 2005. Because articles containing the words cancer or cancerous were more frequent, the 600 most recent of these articles were obtained between 05 October 2005 and 05 November 2005. All articles were considered for analysis, with the exception of duplicated articles from later editions of the same newspaper. The number of articles which were analysed from each newspaper is reported in Table 1. The distribution of articles according to categories of contextual use is shown in Table 2.

'Schizophrenia' was used as a metaphor in $11 \%$ of articles. 'Cancer' was used as a metaphor in $0.02 \%$ of articles. This difference is statistically significant $\left(\chi^{2}=43\right.$, $\mathrm{df}=1, P<0.001$ ).

Table 1 Number of articles analysed from each newspaper

\begin{tabular}{lrr}
\hline Newspaper & \multicolumn{2}{c}{ Number of articles (\%) } \\
\cline { 2 - 3 } & \multicolumn{1}{c}{ Schizophrenia/schizophrenic ( $\boldsymbol{n}=600)$} & Cancer/cancerous $(\boldsymbol{n}=600)$ \\
\hline The Daily Telegraph & $82(13.7 \%)$ & $74(12.3 \%)$ \\
Daily Mail & $119(19.8 \%)$ & $96(16.0 \%)$ \\
The Guardian & $113(18.8 \%)$ & $118(19.7 \%)$ \\
Mirror & $96(16.0 \%)$ & $110(18.3 \%)$ \\
Sun & $62(10.3 \%)$ & $86(14.3 \%)$ \\
The Times & $128(21.3 \%)$ & $116(19.3 \%)$ \\
\hline
\end{tabular}

Table 2 Types of references to schizophrenia and cancer in UK newspapers

\section{Context in which the word is used}

Word used in the article

Schizophrenia/schizophrenic ( $n=600)$

Charity Related
Reference which is educational/prevention/
management related
Medically Inappropriate
Incidental Reference
Medical news
Metaphorical Use
Obituary
Reference to actor/illness in an article of human
interest

Cancer/cancerous ( $n=600$ )

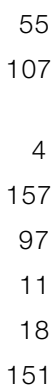

$\begin{array}{rr}0 & 55 \\ 97 & 107 \\ 19 & 4 \\ 159 & 157 \\ 54 & 97 \\ 67 & 11 \\ 1 & 18 \\ 203 & 151\end{array}$


Of the 600 'schizophrenia' articles, 316 contained the noun form (schizophrenia) and 284 contained the adjectival form (schizophrenic). Schizophrenia was used as a metaphor in 12 articles and schizophrenic in 55 articles.

Of the 600 'cancer' articles, 567 contained the noun form (cancer) and 33 contained the adjectival form (cancerous). Cancer was used as a metaphor in 11 articles; Cancerous was not used as a metaphor. There is no statistically significant difference between the use of the nouns as metaphors $\left(\chi^{2}=2.7, \mathrm{df}=1, P=0.1\right)$. The difference between the adjectival use is significant $(P<0.001$, Fisher's exact test).

The majority of metaphorical use of schizophrenia was seen in the broadsheets - $62 \%(41 / 67)$ compared to $38 \%$ $(26 / 67)$ in the tabloids - however, this difference was not statistically significant.

UK newspapers are statistically less likely to use schizophrenia as a metaphor compared with US newspapers, ${ }^{3}$ where 246 of 876 articles used schizophrenia as a metaphor $\left(\chi^{2}=61.9, \mathrm{df}=1, P<0.001\right)$.

Individual UK newspapers differed on the number of articles in which schizophrenia was used metaphorically. The Telegraph and The Times both used the term 19 times, the Daily Mail used it 11 times, The Mirror nine times, The Sun six times, and The Guardian three times.

Metaphorical use was not limited to any particular area of reporting, but it was more common in reporting 'fashion'. For example, a person described herself as having ' . . red hair, freckly skin and green eyes. I also have a bit of a schizophrenic style' in the Daily Mail (03 February 2005). A celebrity described Armani as being '. . versatile and flexible enough to adjust to my sometimes schizophrenic personality.'(The Times, 22 January 2005). In fact, 'fashion, arts and literature' was the category where 19 of 67 metaphorical references were found. The second most common category was sport: in 11 instances, teams or players were described as schizophrenic in their performance. Politics was another area where metaphorical use was used in describing an attitude as schizophrenic; for example, ' . . the ambivalence, which is even schizophrenic, in his attitude to Blair runs deep' (The Daily Telegraph, 07 October 2005). or ' . . . but this government's schizophrenic attitude to alcohol isn't helping' (The Sun, 05 January 2005).

\section{DISCUSSION}

Our study reports that $11 \%$ of use of the term schizophrenia in UK newspapers is metaphorical, and that the public will encounter the use of schizophrenia as a metaphor more often than they will encounter similar use of the term cancer. Our study adds to the suggestion that schizophrenia might be the new illness as metaphor.

\section{Strengths and weaknesses of the study}

In this study the metaphorical use of the adjective and nouns are reported separately. The results shows that the adjective, schizophrenic, is statistically more likely to be used as a metaphor than the noun, schizophrenia $(P<0.001)$. Of the 600 most recent 'cancer' articles, there were only 33 instances of the use of the adjective, cancerous, none of which were metaphorical. Had more adjectival use occurred, we might have found more metaphorical use of the adjective. The representative newspaper sample contained many more instances of the use of the noun, cancer $(n=567)$. This might not reflect the use of the word for the illness in the English language generally. Therefore although this study suggests that schizophrenia is more commonly presented than cancer as a metaphor in the UK newspapers, it cannot suggest that this is true throughout the English language. The American study, which used a similar methodology, does not provide a distribution of the noun and adjectival form of the words. ${ }^{3}$ The separation of adjectival and noun use of the word, as well as the wider use of the words in sources of language other than newspapers, are important considerations for any future studies.

This study suggests that schizophrenia is less likely to be used as a metaphor in UK than US newspapers. This might reflect a different use of the language by the media of these countries; alternatively, it might reflect an awareness of the potential stigmatizing effects of metaphorical use of schizophrenia and a consequent reduction in this use in the seven years since the US sample was obtained (19971998). The different types of newspapers used (the US study included several regional newspapers as well as two national newspapers) is a potential confounder in this comparison.

Sontag describes the process in which an illness associated with metaphor might become adjectival, using leprosy as an example:

'First the subjects of deepest dread (corruption, decay, pollution anomie, weakness) are identified with the disease. The disease itself becomes a metaphor. Then in the name of the disease the horror is imposed on other things. The disease becomes adjectival. Something is said to be disease-like, meaning that it is disgusting or ugly. In French, a mouldering stone façade is still lepreuse.' 6

This study provides examples which show that a similar process might have occurred for schizophrenia. The word appears to stand for all things weird, contradictory or unpredictable. The compact Oxford English Dictionary describes 'schizophrenic' as an adjective meaning '1. suffering from schizophrenia. 2 (in general use) characterized by 
inconsistent or contradictory elements.' (Compact Oxford English Dictionary online). This suggests metaphorical usage of the term is accepted in English and is not specifically sensationalist. Our research supports this, as there was no statistical difference between the broadsheet and tabloid use of the term. The use of schizophrenia as a metaphor for contradictory elements might add to the stigma of the illness. Alternatively, an illness which is stigmatized might be more likely to be metaphorized. Sontag suggested that as the aetiology of an illness becomes clearer, the stigma and metaphorization reduce. The apparent reduction in metaphorization of cancer reported in this study and the US study might be related to the advent of more effective treatment and better recovery.

Although Sontag's claim that the stigma which results from the metaphorical use of cancer reduced patients to a state of silence and disgrace has been challenged, ${ }^{2}$ examples from this study showed that metaphorical use can be distressing - for example, an aggrieved carer wrote a letter of complaint to The Mirror after a soap actress described her eating habits as 'schizophrenic', saying that if a family member of the actress had schizophrenia she would not use the term so lightly (The Mirror 30 November and 03 December 2004). Hoffman-Richter et al. ${ }^{4}$ identify a similar letter to the editor of The Guardian which seeks to eliminate the notion of schizophrenia as a metaphor. Interestingly, the Mirror and the Guardian were newspapers with low misuse of the term.

Words have immense power to create stigma. The negative impression of the term 'schizophrenia' prevented $37 \%$ of Japanese psychiatrists from sharing the diagnosis with their patients. ${ }^{7}$ This led to the Japanese Society of Psychiatry and Neurology (analogous to the Royal College of Psychiatrists) changing the name of the illness from seishi buntetsu byo (split-mind disorder) to togo shiccho sho (loosened association disorder) at the World Psychiatric Association congress in $2002 .^{8}$

\section{Implications}

Sontag suggested the purest way to think of an illness is to strip it of its metaphors. It is difficult to prevent the use of schizophrenia as a metaphor. The use of the word as a metaphor for unpredictability and chaos suggests that the public might be misinformed about the nature of the illness. This makes it important for clinicians to explore the understanding that patients, carers and the public might have about the word which we use as a diagnosis.

The philosopher Friedrich Nietzche sums it up in Daybreak:
'To calm the imagination of the invalid, so that at least he should not, as hitherto, have to suffer more from thinking about his illness than from the illness itself - that, I think, would be something! It would be a great deal.' 9

Competing interests $\mathrm{AKC}$ is a master's candidate at Nottingham University and this work forms part of a larger project looking at the portrayal of schizophrenia in the UK national and local newspapers. GAD has no interests to declare.

Funding This work was conducted as part of AKC's masters degree research at the University of Nottingham. Nottinghamshire Healthcare NHS Trust provides funding for trainees on the psychiatric training rotation to attend this course part-time.

Ethical approval No patient-related information was accessed in this study. The information used was from newspapers in the public domain and previously published work. No ethical approval was required.

Guarantor $\mathrm{AKC}$ is the guarantor of this work and accepts full responsibility for the work, the conduct of the study, access to the data and control over the decision to publish.

Acknowledgments This work was presented at the Annual General Meeting of the Trent Division of the Royal College of Psychiatrists in September 2006.

\section{REFERENCES}

1 Sontag S. Illness as Metaphor. New York: Farrar, Strauss and Giroux, 1978

2 Clow B. Who's afraid of Susan Sontag? Or, the myths and metaphors of cancer reconsidered. Soc Hist Med 2001;14:293-312

3 Duckworth K, Halpern JH, Schutt RK, Gillespie, C. Use of Schizophrenia as a metaphor in US newspapers. Psychiatr Serv 2003;54:1402-04

4 Hoffman- Richter U, Forrer F, Finzen A. Die Schizophrenie in der 'Frankfurter Allgemein Zeitung'-Eine Medienanalyse. Psychiatr Prax 2003;30:4-7

5 Hoffman-Richter U, Alder B, Hinselmann V, Finzen A. Schizophrenia as featured in the 'Neue Zurcher Zeitung'. Psychiatr Prax 1998;25:14-18

6 Sontag S. Illness as Metaphor and AIDS and Its Metaphors. London: Penguin Classics, 1991:60

7 Kim Y. Renaming the term schizophrenia in Japan. Lancet North Am Ed 2002;360:879

8 OnoY, Satsumi Y, Kim Y, et al. Schizophrenia: Is it time to change the term? Psychiatry Clin Neurosci 1999;53:335-41

9 Nietzsche F (1881) Daybreak: Thoughts on the Prejudices of Morality. In: Clark M, Leiter B, eds. Cambridge Texts in the History of Philosophy. Cambridge: Cambridge University Press, 1997 